\title{
Stability and flip bifurcation of a three dimensional exponential system of difference equations
}

\author{
Chrysoula Mylona ${ }^{1}$, Garyfalos Papaschinopoulos ${ }^{1}$, and Christos Schinas ${ }^{1}$ \\ ${ }^{1}$ Democritus University of Thrace School of Engineering
}

October 20, 2020

\begin{abstract}
In this paper, we study the stability of the zero equilibrium and the occurrence of flip bifurcation on the following system of difference equations: $\backslash\left[\mathrm{x}_{-}\{\mathrm{n}+1\}=\mathrm{a}_{-} 1 \backslash \operatorname{frac}\left\{\mathrm{y} \_\mathrm{n}\right\}\left\{\mathrm{b}_{-} 1+\mathrm{y} \_\mathrm{n}\right\}+\mathrm{c}_{-} 1 \backslash \operatorname{frac}\left\{\mathrm{x} \_n e^{\wedge}\left\{\mathrm{k}_{-} 1-\mathrm{d}_{-} 1 \mathrm{x} \_n\right\}\right\}\left\{1+\mathrm{e}^{\wedge}\left\{\mathrm{k}_{-} 1-\mathrm{d}_{-} 1 \mathrm{x}_{-} \mathrm{n}\right\}\right\}, \backslash\right] \backslash \backslash \backslash \mathrm{y}_{-}-$

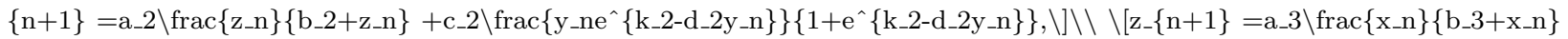
$+\mathrm{c} \_3 \backslash$ frac $\left.\left\{\mathrm{z} \_n \mathrm{e}^{\wedge}\left\{\mathrm{k} \_3-\mathrm{d} \_3 \mathrm{z} \_n\right\}\right\}\left\{1+\mathrm{e}^{\wedge}\left\{\mathrm{k} \_3-\mathrm{d} \_3 \mathrm{z} \_\mathrm{n}\right\}\right\} \backslash\right]$ where $\$ \mathrm{a} \_\mathrm{i} \$, \$ \mathrm{~b} \_\mathrm{i} \$, \$ \mathrm{c} \_\mathrm{i} \$, \$ \mathrm{~d} \_\mathrm{i} \$, \$ \mathrm{k} \_\mathrm{i} \$$, for $\$ \mathrm{i}=1,2,3 \$$, are real constants and the initial values $\$ \mathrm{x}_{-} 0 \$, \$ \mathrm{y}_{-} 0 \$$ and $\$ \mathrm{z}_{-} 0 \$$ are real numbers. We study the stability of this system in the special case when one of the eigenvalues is equal to -1 and the remaining eigenvalues have absolute value less than 1 , using center manifold theory.
\end{abstract}

\section{Hosted file}

stability and bifurcation.pdf available at https://authorea.com/users/368914/articles/487908stability-and-flip-bifurcation-of-a-three-dimensional-exponential-system-of-differenceequations 